\title{
How Can Social Branding Mitigate Racism Among Fans in Sports? A Q-sort Analysis on the Value of Social Branding Campaigns as Vehicles for Reducing Racism Among Soccer Fans
}

\author{
Dr. Vidar Stevens (corresponding author) \\ Mulier Instituut \\ Herculesplein 269, 3584 AA Utrecht, the Netherlands \\ Rens Cremers, MSc. \\ Mulier Instituut \\ Herculesplein 269, 3584 AA Utrecht, the Netherlands
}

Received: Feb. 14, 2021 Accepted: Mar. 11, 2021 Online published: Mar. 21, 2021

doi:10.5296/jpag.v11i1.18299

URL: https://doi.org/10.5296/jpag.v11i1.18299

\begin{abstract}
Social branding is a new governance strategy in the field of sport. National governments and sport associations, for instance, use branding to reach out to fans and alter their perceptions of racism in sport. But how do fans, as a target group, actually value this governance strategy? This article zooms in on the purpose of social branding, as perceived by fans as a target group in a social branding campaign on racism in soccer in the Netherlands. The Q-sort methodology was used to study the subjective viewpoints of 29 soccer fans of different professional sport clubs. The analysis reveals that soccer fans prefer a transparent branding process in which they are recognized as coproducers of the brand and can add their story to the brand message that is conveyed to target audiences.
\end{abstract}

Keywords: racism, social branding, public policy, collaboration, governance 


\section{Introduction}

In February 2020, in a clash between Chelsea FC and Tottenham Hotspur FC, officials were forced to stop the play. It was not because of a yellow card or red card. It was because racism had reared its ugly head. Antonio Rudiger, a Chelsea FC defender, informed the referee that he believed he had been subjected to racist monkey chants from rival Tottenham Hotspur FC supporters. The referee, Anthony Taylor, used a new protocol from the UEFA (Union of European Football Associations), the governing body of European soccer, to stop play. The new protocol, introduced in October 2019, allows for the referee to abandon the match if racist behavior continues after two warnings issued by a stadium announcer.

This was not a standalone incident. In other countries, racism in soccer has also become a major talking point. In the Netherlands, for example, the Dutch national soccer team issued a strong anti-racism statement on social media in November 2019, ahead of a game against Estonia. A photo, which went viral on social media, pictures the squad in a circle touching hands following a racist incident in Den Bosch, in which the match of FC Den Bosch against S.V. Excelsior was suspended for a time when one of the S.V. Excelsior players was subjected to racist abuse. The incident prompted the Dutch authorities to develop a new policy strategy to help eradicate the problem.

In the coming years, the Dutch authorities are hoping to clamp down on racism in soccer. Fourteen million euros have been made available for investment in the fight against racism in soccer. A 3-year plan to tackle discrimination in the game was unveiled by the government in collaboration with the Dutch football association on February 8, 2020. The plan included several measures that focus on aspects of prevention, identification, and enforcement. One of the proposed measures is organizing a social branding campaign. In this article, we study the value of a social branding campaign for tackling racism among soccer fans.

\section{Theory: The Phenomenon of Social Branding and Brand Communities}

Social branding is a promising, upcoming governance strategy (Stevens, 2019; Stevens et al., 2020). A social brand is a deliberately developed symbolic construct to identify a phenomenon (e.g., a societal problem like racism in sport) and differentiate it from similar phenomena by adding meaning, often positive, to it (Eshuis \& Klijn, 2012). An example of a social brand is the "Say No to Racism" campaign of the Fédération Internationale de Football Association (FIFA), which aims to ensure that supporters are more accepting of players with darker skin. Social brands are used to communicate with and bind (create brand loyalty through establishing emotional bonds) stakeholders, and even motivate them to contribute to solutions to severe societal problems (Stevens et al., 2020).

Branding processes can be organized collaboratively (Klijn \& Stevens, 2021). Collaborative processes of branding allow stakeholders (e.g., soccer fans) to develop a shared brand identity and add or upload their own contributions to the brand. In this way, brand communities can be created (Muniz \& O'Guinn, 2001). Brand communities are groups of stakeholders who feel they have a shared identity by sharing symbols or feeling the same emotional attachment to the branded phenomenon (Stevens et al., 2020; Stevens, 2019). 
Within these communities, brands also play a role in identity-formation processes at the individual level because individuals can use brands to build and shape their personal identities. In addition, building brand communities can lead to more resilience in society. That is to say, brand communities can ideally mobilize people and sustain participation and collective action to tackle societal problems, like racism in sport. In this sense, brand communities contribute to society's governance capacity to tackle societal problems. Ideally, brand communities can even stimulate the emergence of public self-organization as a response to traditional, hierarchical governance approaches by public organizations.

So far, the idea of brand communities as vehicles to organize (and legitimize) collective action to address societal problems has not been empirically scrutinized. The lack of empirical studies on the notion of brand communities is striking because it means that we do not have insights into how public organizations can foster the emergence of brand communities, under what circumstances a wider public will feel emotionally attached to a brand community, and how a social branding campaign can be used as a strategy to foster collective action to tackle societal problems. To this end, this article explores how soccer fans in the Netherlands respond to a social branding campaign about racism in the sport and whether they believe a brand community can be created to address the problem.

The article builds on 29 interviews with soccer fans of different professional soccer teams in the Netherlands. The focus of the interviews was on the ambition of the Dutch football association; The Ministry of Health, Welfare and Sports ('the Ministry'); and the 38 professional soccer teams in the Netherlands to target the problem of racism among fans by organizing a social branding campaign. Specifically, this article aims to find an answer to the research question: How can social branding mitigate racism among soccer fans?

To capture the perceptions of soccer fans on the issue of branding and racism, we made use of the Q-sort methodology. The Q-sort methodology, originally developed in the field of psychology, allows one to systematically study the subjective viewpoints of individuals (McKeown \& Thomas, 2013; Lee, 2017). The remainder of the article is structured as follows. First, we elaborate on the Q-sort methodology and we describe the data collection and data analysis processes. Second, we present the findings of our study. Finally, we highlight the implications of our findings for using social branding as a strategy to collaborate with professional soccer clubs and fans to reduce racism in the sport.

\section{Methodology: Q-sort Analysis as a Way to Capture Perceptions of Respondents}

To identify the perspectives of soccer fans on the value of a social branding campaign as a vehicle for reducing the number of racist expressions or chants among soccer fans, we used the Q-sort methodology. The Q-sort methodology is designed to study the subjective viewpoints of individuals, such as their feelings, opinions, or beliefs (McKeown \& Thomas, 2013; Lee, 2017). To capture these viewpoints, respondents (the "P-set") are asked to rank a set of statements (the "Q-set") to determine what they find most important (Watts \& Stenner, 2012). After the statements have been sorted, a factor analysis is used to distinguish factors: clusters of participants who rank the statements in a similar fashion. 


\section{The Q-Set: The Statements}

The first stage of a Q-sort data collection process is to collect statements and select a sample of them to present to the respondents. These statements can be derived from various sources (Jeffares \& Skelcher, 2011). We used a policy-oriented starting point for the development of our statements, using policy documents and vision documents to draft them (Jeffares \& Skelcher, 2011). The statements represent the broad political discussion about how to use and organize a social branding campaign in the Netherlands to tackle the problem of racism among soccer fans. The statements focus on the aspects of ownership, governance, brand communication, the brand message, impact, and the role of professional soccer clubs, teams, players, and fan organizations in the campaign.

To check whether the statements connect with the experience of practitioners, we presented the statements to two scholars with extensive experience in racism research in the Dutch soccer context. After each session, we refined the statements to ensure that all relevant issues in the debate were included and that the statements were understandable and meaningful for the respondents. The list of statements is presented in Table 1. We presented the statements to the respondents in the same order to ensure consistency in the interview.

\section{The P-Set: The Respondents}

The second stage of a Q-sort data collection process is to select individuals to participate in the study. Our respondents were soccer fans who were supporters of one of the professional teams in either the Dutch Eredivisie or the Keuken Kampioen Divisie (the first two tiers of professional leagues in the Netherlands). In our selective sampling procedure, we had two conditions: a soccer fan had to have been a supporter for more than a season, and we had to have a selection of supporters of a variety of professional soccer clubs (i.e., not only the major clubs like AFC Ajax Amsterdam, SC Feyenoord Rotterdam, and PSV Eindhoven). We aimed to include both dedicated soccer fans ("the hooligans of the club," according to Respondent 8) and more recreational soccer fans ("the family that goes out to watch the game," according to Respondent 23). Out of the 29 respondents, 16 considered themselves to belong to the hardcore supporter category.

Table 1. The 24 statements of the Q-sort

\begin{tabular}{ll}
\hline Number & \multicolumn{1}{c}{ Statement } \\
\hline 1 & A social branding campaign about racism in sport bans racism from soccer. \\
\hline 2 & A social branding campaign about racism in sport fosters dialogue among soccer fans. \\
\hline 3 & $\begin{array}{l}\text { A social branding campaign about racism in sport increases awareness among soccer } \\
\text { fans. }\end{array}$ \\
\hline 4 & A social branding campaign about racism in sport makes soccer fans more tolerant. \\
\hline 6 & $\begin{array}{l}\text { A social branding campaign about racism in sport makes soccer fans report racism } \\
\text { more quickly (through the digital app). }\end{array}$ \\
\hline 7 & $\begin{array}{l}\text { A social branding campaign about racism in sport has no effect on the behaviors and } \\
\text { attitudes of soccer fans. }\end{array}$ \\
\hline
\end{tabular}


branding campaign about racism in sport.

8 The football association has to collaborate with professional soccer clubs to design a social branding campaign on racism in sport.

9 Professional soccer clubs are the most suitable stakeholders to organize social branding campaigns about racism in sport.

10 Neither the football association nor professional soccer clubs must organize social branding campaigns on racism in sport.

11 Social branding campaigns about racism in sport must be organized by fan organizations.

\begin{tabular}{ll}
\hline 12 & A social branding campaign about racism in sport can only be developed by experts. \\
\hline 13 & $\begin{array}{l}\text { Soccer players who have experienced racism must be given a big platform in a social } \\
\text { branding campaign. }\end{array}$ \\
\hline 15 & $\begin{array}{l}\text { In a social branding campaign on racism in sport, a one-sided, positive message about } \\
\text { diversity should be communicated. }\end{array}$ \\
\hline 16 & $\begin{array}{l}\text { Mentioning facts and figures about racism in sport is the only way to make supporters } \\
\text { more aware of the problem. }\end{array}$ \\
\hline 17 & $\begin{array}{l}\text { The personal experiences of soccer players must be emphasized in a social branding } \\
\text { campaign on racism in sport. }\end{array}$ \\
\hline 18 & A message to supporters about racism in sport should be simple and consistent. \\
\hline 19 & $\begin{array}{l}\text { A message to supporters about racism in sport must align with the culture of a } \\
\text { professional soccer club. }\end{array}$ \\
\hline 20 & $\begin{array}{l}\text { In a social branding campaign, there must be room for different perspectives on racism } \\
\text { and diversity in sport. }\end{array}$ \\
\hline 21 & Team captains are the best brand ambassadors to discuss the issue of racism in sport. \\
\hline 22 & $\begin{array}{l}\text { Including the club logo of a professional soccer team strengthens a social branding } \\
\text { campaign on racism in sport. }\end{array}$ \\
\hline 23 & $\begin{array}{l}\text { Especially players who have not experienced racism must play a big role in a social } \\
\text { branding campaign on racism in sport. }\end{array}$ \\
\hline 24 & $\begin{array}{l}\text { Showing a social branding campaign about racism in sport in TV programs and talk } \\
\text { shows, will make it easier to discuss the topic. }\end{array}$ \\
\hline
\end{tabular}

\section{Data Collection and Analysis}

The data were collected between May 20 and June 20, 2020. This was in the aftermath of George Floyd's death, which led to major societal discussions and protests in the Netherlands. The data collection was completed just two days before a national debate on racism in soccer, sparked as a consequence of a racist insult on a sport talk show in the Netherlands. This is important to highlight because many of the respondents reflected on the societal debate in the Netherlands after George Floyd's death in the interviews but were not influenced by the statements made by influencers on television after the sport talk show incident. Therefore, we are confident that the views of the respondents in our sample also represent their genuine, personal views on racism in sport. 


\section{Al Macrothink}

Journal of Public Administration and Governance

ISSN 2161-7104

2021, Vol. 11, No. 1

The statements were sorted face-to-face to give respondents the opportunity to reflect on the statements, and so the authors could gain additional information about the respondents' trains of thought during the sorting process. Therefore, the sorting of the statements was followed by a short interview. On average, these meetings lasted 1 hour. To guarantee the respondents' anonymity, respondents are referred to by number rather than by name. The statements were sorted in three rounds, as follows. In the first round, respondents were asked to sort the statements into three piles that represented their degree of agreement (disagree, neutral, agree). In the second round, the respondents went over the same statements again, but were forced to make more restricted choices by placing statements in a triangular shape, where the leftmost and rightmost corners of the triangle represented the statements they agree with most $(+3)$ and least $(-3$; see Figure 1$)$. This means that even though respondents may have agreed with multiple statements, they had to select the statements they found most important, thereby choosing what mattered most to them. In the third round, the respondents looked at their Q-sort and were offered a final opportunity to make alternations to their sorting. Also, they were asked to reflect upon the statements they agreed with most $(+3)$ and least $(-3)$. The results of the Q-sort data collection and analysis are presented in the next section.

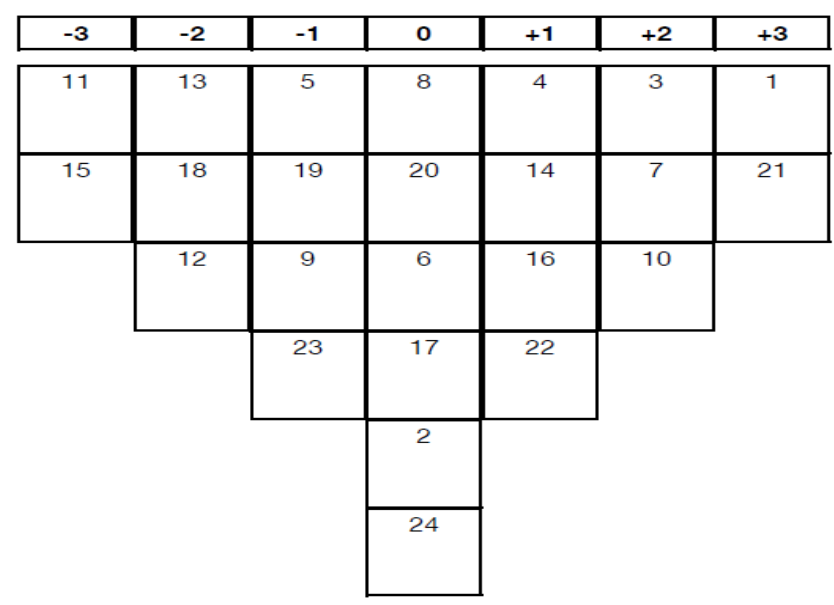

Figure 1. Example of a completely sorted Q-sort

\section{Results}

After collecting all 29 Q-sorts, we performed a factor analysis to identify groups of respondents who shared similar perceptions. We used Ken-Q Analysis: an online software program designed to analyze data resulting from Q methodological research (Banasick, 2019). The factor analysis resulted in the extraction of four factors. More than four factors would result in the inclusion of factors with too low an eigenvalue $(<1.5)$, while less than four factors would result in too much overlap between the factors (with correlations of $>0.53$ ). Out of the 29 respondents, 23 are significantly associated with one of the four factors (p $<.01$ ). Information about the analyses (e.g., explained variance, eigenvalues, pairwise correlations) can be retrieved from this article's Harvard Dataverse (Stevens, 2021). In total, the explained variance is $51 \%$, which fulfils the criteria of a well-executed Q-analysis (Jeffares \& Skelcher, 2011, p. 199). Because each factor represents a different group of 
respondents with shared perceptions, we refer to the factors as profiles. Below, we present and describe the four profiles.

\section{Profile 1: A Top-Down Organized Branding Campaign With a One-Sided Brand Message}

Profile 1 has an eigenvalue of 8.86 and explains $17 \%$ of the study variance after rotation. Nine respondents are significantly associated with this factor $(\mathrm{p}<.01)$. Respondents belonging to this profile find it of utmost importance that the branding campaign of the football association, the Ministry, and the professional soccer clubs in the Netherlands aim to make soccer fans more aware of the pain and hurt players experience when being confronted with racist chants or insults from fans (Statement 3: $+2^{1}$; Statement 16: +2 ). Statement 3 scored significantly more positively than the other profiles at $\mathrm{p}<.05$.

Respondents associated with this profile are of the opinion that the football association must collaborate with professional soccer clubs in designing and implementing a social branding campaign on racism in sport (Statement 8: +3 ). More than other profiles, respondents associated with Profile 1 indicate that the football association must obligate professional soccer clubs to join the social branding campaign (Statement 7: 0, but significantly more positive compared to other profiles at $\mathrm{p}<.01$ ).

This more stringent spirit of collaboration is associated with ensuring that there is no room for a multitude of opinions regarding racism and diversity in sport (Statement 20: -2 , significantly less positive than in the other profiles at $\mathrm{p}<.01$ ). Instead, the brand message that will be communicated to soccer fans must be a one-sided, pro-diversity brand message (Statement 14: +2). As such, respondents associated with Profile 1 prefer a branding campaign organized top-down that sends out one clear pro-diversity message to soccer fans.

\section{Profile 2: A TV-Based Branding Campaign With a Simple and Factual Brand Message}

Profile 2 has an eigenvalue of 2.18 and explains $12 \%$ of the study variance after rotation. Four respondents are significantly associated with this factor $(\mathrm{p}<.01)$. Respondents belonging to this profile highlight that only when soccer-related TV-programs and talk shows are used as platforms to send out the brand message and the message is simple and factual (i.e., includes facts and figures) is there a small chance of soccer fans becoming more aware of the pain and hurt players experience when being confronted with racism in soccer (Statement 24: $+3^{2}$; Statement 18: $+3^{3}$; Statement 15: $+2^{4}$; Statement 3: +1 ). These respondents are, however, very skeptical about the effects of a branding campaign. Nevertheless, more than in other profiles, the respondents of Profile 2 scored Statement 6 significantly lower $(\mathrm{p}<.01 ;-3)$.

\footnotetext{
${ }^{1}$ The numbers in the parentheses refer to the statement number, followed by the position of the statement in the sorting scheme, ranging from -3 to +3 .

${ }^{2}$ Statement scored significantly more positively compared to the other profiles at $\mathrm{p}<.01$.

${ }^{3}$ Statement scored significantly more positively compared to the other profiles at $p<.05$.

${ }^{4}$ Statement scored significantly more positively compared to the other profiles at $p<.01$.
} 
Furthermore, Profile 2 highlights that the role of fan organizations of individual clubs in the campaign should be limited and that, if there were to be a campaign, "experts" should best be hired to draft the branding process and brand message. Including the logo of a soccer club in a branding campaign does not seem to have a positive effect on its impact, according to respondents associated with Profile 2: "It does not provide me with a greater feeling of attachment to the campaign" (Respondent 7). To this end, Profile 2 indicates that the brand message must present the severity of the problem and how often racism occurs in soccer, otherwise a branding campaign will not have any effect.

\section{Profile 3: A Supporters' Campaign Including a Multitude of Voices and Perspectives}

Profile 3 has an eigenvalue of 1.98 and explains $10 \%$ of the study variance after rotation. Five respondents are significantly associated with this profile $(\mathrm{p}<.01)$. Respondents belonging to this factor highlight that without room for a multitude of voices and perspectives on racism and diversity in the campaign, there will never be a genuine dialogue among soccer fans (Statement 20: +3 ; Statement 2: +2 ). Moreover, the respondents indicate that it is important that the campaign be organized by fan organizations (Statement 11: +3 ). The three statements are "positive" distinguishing statements at $\mathrm{p}<.01$, implying that the $\mathrm{z}$-scores of statements 20,2 , and 11 in this profile are ranked significantly higher than in the other profiles.

The respondents associated with Profile 3 see a limited role for the football association and the professional soccer clubs in designing and implementing a campaign (Statement 7: -1 ; Statement 9: 0), and no role at all for experts (Statement 12: $-3^{5}$ ). Respondents of Profile 3 mostly highlight the way in which the message must be communicated and what the message should consist of. As well as focusing on a multitude of voices and perspectives, the campaign should be communicated simply and clearly (Statement 18: +2 ), and align with the culture of the soccer club (Statement 19: +1 ). Profile 3 is, as such, not so much a process-oriented perspective but rather one of respondents with stronger views about the substantive complexity of the topic of racism in sport. Respondents associated with Profile 3 emphasize that all classes and colors of society meet in soccer settings: "therefore, all these colors and IQ levels must have an equal opportunity to leave their mark on the branding campaign" (Respondent 14).

\section{Profile 4: A Club's Campaign to Address Racism Among Fans}

Profile 4 has an eigenvalue of 1.59 and explains $12 \%$ of the study variance after rotation. Five respondents are significantly associated with this factor $(\mathrm{p}<.01)$. More than in other profiles, respondents belonging to this profile highlight that a branding campaign against racism in the sport will have a moderate effect on the behaviors and perceptions of soccer fans (Statement 6: $0^{6}$ ). Respondents believe that there are, however, certain preconditions that will influence the effect of the social branding campaign. First, the message of the branding campaign must align with the culture of the club (Statement 19: $+3^{7}$ ). Second, a captain, as a club's

\footnotetext{
${ }^{5}$ Statement scored significantly more negatively compared to the other profiles at $p<.01$.

${ }^{6}$ Statement scored significantly more positively compared to the other profiles at $p<.01$.

${ }^{7}$ Statement scored significantly more positively compared to the other profiles at $\mathrm{p}<.01$.
} 
ambassador, must play a central role in the campaign (Statement 21: +2 ). Third, the logo of the professional club must be used in the campaign because it is a symbol that increases supporters' feelings of attachment to the campaign (Statement 22: +2). Fourth, the professional soccer club must organize the branding campaign themselves (Statement 9: $+1^{8}$ ). Public officials should not be under the illusion that a campaign will successfully ban racism from the sport (Statement 1: $-3^{9}$ ), but by considering these preconditions, soccer fans will become more aware of the pain and hurt players feel when they experience racists chants or comments. Therefore, Profile 4 highlights the best way to organize a successful club campaign.

\section{Discussion: Comparing the Four Profiles}

Table 2 summarizes the main similarities and differences between the profiles. The Q-sort analysis shows that there is one commonality between the four profiles: No matter how a campaign is organized, it must communicate the amount of pain and suffering victims of racism in sport experience. This insight becomes clear when performing the consensus statement analysis after the factor rotation. Statement 16 is the only statement that does not distinguish between any pair of factors at a significance level of $p<.01$. The profiles relatively differ, however, when it comes to the effect of the branding campaign, the brand message that must be communicated, and the governance structure of designing and implementing the social branding campaign.

Table 2. Similarities and differences between the four profiles

\begin{tabular}{|c|c|c|c|c|}
\hline & Profile 1 & Profile 2 & Profile 3 & Profile 4 \\
\hline $\begin{array}{l}\text { Effect of a } \\
\text { social } \\
\text { branding } \\
\text { campaign }\end{array}$ & $\begin{array}{l}\text { Soccer fans are made } \\
\text { more aware of the pain } \\
\text { and hurt players } \\
\text { experience when being } \\
\text { confronted with racist } \\
\text { chants or insults from } \\
\text { fans. }\end{array}$ & $\begin{array}{l}\text { A very skeptical perspective: } \\
\text { a limited chance that the } \\
\text { campaign will have any } \\
\text { effect. There is a very small } \\
\text { chance, when executed } \\
\text { properly, that fans will } \\
\text { become more aware of the } \\
\text { pain and hurt players } \\
\text { experience when being } \\
\text { confronted with racist chants } \\
\text { or insults from fans. }\end{array}$ & $\begin{array}{l}\text { No explicit effect, but } \\
\text { when respondents must } \\
\text { mention an effect, it is } \\
\text { that the campaign can } \\
\text { foster genuine dialogue } \\
\text { among soccer fans. }\end{array}$ & $\begin{array}{l}\text { A moderate effect } \\
\text { on the behaviors } \\
\text { and perceptions } \\
\text { regarding racism in } \\
\text { sport, but racism } \\
\text { will not be banned } \\
\text { from the sport. }\end{array}$ \\
\hline $\begin{array}{l}\text { Type of brand } \\
\text { message that } \\
\text { must be } \\
\text { communicated }\end{array}$ & $\begin{array}{l}\text { A one-sided, } \\
\text { pro-diversity message } \\
\text { that is not developed } \\
\text { by experts. There must } \\
\text { be no references to } \\
\text { facts or statistics about }\end{array}$ & $\begin{array}{l}\text { A simple message that } \\
\text { includes facts about the } \\
\text { prevalence of racism against } \\
\text { players in soccer. There must } \\
\text { be no sentimental undertone } \\
\text { within the message - or have }\end{array}$ & $\begin{array}{l}\text { The brand message } \\
\text { must allow room for a } \\
\text { diversity of opinions } \\
\text { and sentiments. At the } \\
\text { same time, the message } \\
\text { must be as simple and }\end{array}$ & $\begin{array}{l}\text { The brand message } \\
\text { must align with the } \\
\text { culture, stories, } \\
\text { and values of the } \\
\text { club to have an } \\
\text { impact on soccer }\end{array}$ \\
\hline
\end{tabular}

\footnotetext{
${ }^{8}$ Statement scored significantly more positively compared to the other profiles at $\mathrm{p}<.01$.

${ }^{9}$ Statement scored significantly more negatively compared to the other profiles at $p<.01$.
} 


\section{Mll Macrothink Mnstitute"}

\begin{tabular}{|c|c|c|c|c|}
\hline & $\begin{array}{l}\text { the prevalence of } \\
\text { racism against players } \\
\text { in soccer. }\end{array}$ & $\begin{array}{l}\text { the quality to cause feelings } \\
\text { of sadness or sympathy (no } \\
\text { pathos). }\end{array}$ & clear as possible. & fans. \\
\hline $\begin{array}{l}\text { Governance } \\
\text { set-up of the } \\
\text { branding } \\
\text { campaign }\end{array}$ & $\begin{array}{l}\text { A top-down organized } \\
\text { social branding } \\
\text { campaign, where sport } \\
\text { clubs must be obligated } \\
\text { to comply with strict } \\
\text { rules and regulations } \\
\text { regarding the execution } \\
\text { of the branding } \\
\text { campaign to ensure } \\
\text { uniformity. }\end{array}$ & $\begin{array}{l}\text { TV programs must be used } \\
\text { as platforms to spread the } \\
\text { brand message. Captains } \\
\text { must be used as brand } \\
\text { ambassadors or influencers. }\end{array}$ & $\begin{array}{l}\text { A bottom-up organized } \\
\text { branding campaign, } \\
\text { with no role for experts, } \\
\text { and only a limited role } \\
\text { for the football } \\
\text { association and soccer } \\
\text { clubs. The fan } \\
\text { organizations must } \\
\text { oversee and coordinate } \\
\text { the branding campaign. }\end{array}$ & $\begin{array}{l}\text { A campaign } \\
\text { organized by the } \\
\text { soccer clubs that } \\
\text { uses the logo of the } \\
\text { club and the } \\
\text { captain as symbols } \\
\text { to make fans feel } \\
\text { they are part of the } \\
\text { branding process. }\end{array}$ \\
\hline
\end{tabular}

Journal of Public Administration and Governance ISSN 2161-7104 2021, Vol. 11, No. 1

To elaborate, Profiles 2 and 3 are very skeptical about the potential effects of a branding campaign. Respondents associated with these perspectives do not view a social branding campaign as the ultimate vehicle for changing a soccer fan's behavior or perception. According to this profile, although the chance is very limited, a social branding campaign might make fans more aware of the severity and impact of racism in sport and foster a genuine debate among fans. Respondents associated with Profiles 1 and 4, however, feel that a social branding campaign can make soccer fans more aware of the impact of racism and might even have a moderate effect on the behaviors of fans. Respondents from the four profiles agree that it is an illusion to think that racism can be completely banned from the sport. As Respondent 17 stated, "there are always idiots that will use racism to get under the skin of the opponent, and if this idiot is a leader of a group, the sheep will follow the leader."

When we look at the brand message, Profile 1 has a particularly explicit idea of how the brand message must be communicated. The brand message, according to the respondents associated with Profile 1, must be a one-sided, pro-diversity message that is not developed by experts and has no reference to facts or statistics about the prevalence of racism against players in sport. In contrast, Profile 2 argues that a brand message should include facts about the prevalence of racism against players in sport to avoid too much pathos in the communications with fans. Profile 4 attaches a lot of value to aligning the social branding campaign with the norms, values, history, stories, and culture of the clubs. These are already symbols with which soccer fans identify, so references to these symbols will help a social branding campaign, according to Respondent 11, "get the brand message into a fan's brain." Respondents associated with Profile 3 mostly emphasize that there must be room for multiple voices and perspectives in a social branding campaign. Nonetheless, they recognize that a brand message must be as simple and clear as possible. These two statements are somewhat contradictory.

Regarding the governance of the social branding campaign, collaboration seems preferable among all profiles. However, the respondents do not seem to concur about the way in which the collaboration should be organized, or which stakeholders should collaborate. Profile 3 indicates a preference for the fan organizations of the individual professional clubs to play an 
active organizing role. Profile 1, in contrast, calls for a campaign that is organized top-down, where sport clubs are forced to participate and follow strict rules and regulations to ensure uniformity. Profile 1 argues that the football association should oversee the social branding campaign, while Profile 3 argues that the football association should have a marginal role in its design and execution. Notably, respondents of Profile 2 argue that TV shows must be in charge of the branding campaign to reach as many soccer fans as possible. Profiles 2 and 4, for different reasons, prefer that the captain of a team plays an active role as a conveyor of the branding message in the social branding campaign.

\section{Conclusion}

The Q-sort analysis revealed that there are various ways to mitigate racism among soccer fans through social branding campaigns. We identified four profiles that represent four different types of social branding campaign. A brand manager must be aware of these different forms of social branding. In our view, the four branding campaigns can coexist because they address different target audiences and are designed for different purposes. Profile 1 is the standard stadium campaign, which aims to address the average soccer fan who comes to watch a live match. Profile 2 represents the TV campaign, which oftentimes is launched to reach a bigger audience. Profile 3 highlights the fan campaign and describes how within fan organizations a campaign can influence existing norms and values. Profile 4 is the branding campaign of individual soccer clubs, in which they can stress that they do not tolerate racism within their club. It is important that the football association, the Ministry, and the 38 professional soccer clubs blend these four types of social branding campaign to ensure the greatest branding effect on the perceptions of soccer fans in the Netherlands.

From a public policy and governance stance, this study further shows that social branding and its attempt to interact with fans to tackle the issue of racism in the sport involves shifting how the football association and public authorities view their roles; transforming from top-down marketing managers to non-hierarchical facilitators looking for meaningful ways to include fans, fan organizations, players, experts, and soccer clubs in decision-making spaces. A question that we did not touch upon in the study but that regularly arose in the interviews is whether triggering positive associations in fans' minds through marketing activities is an appropriate, legitimate, and desirable way to influence public opinion about a societal problem, like racism in sport.

This research has certain limitations. One of the limitations of the study is that we looked at a social branding campaign on racism in soccer in only one country: the Netherlands. The advantage of such a research design is that we looked at professional soccer clubs and fans who experienced the same, well-defined branding campaign. Nevertheless, this research design brings issues of generalizability. Respondents from different countries and different sport traditions may have other opinions about notions of racism, diversity, or discrimination, which can lead to diverging views on how to organize a social branding campaign about racism in soccer. A second limitation is that we looked at the perceptions of respondents and not their actions. This means that whether a branding campaign impacts fans' behaviors is still open to question. This said, we believe that our empirical contribution, showing how fans 
perceive the social branding activities of soccer associations and public authorities, is valuable for the maturation of the research field.

\section{References}

Banasick, S. (2019). Ken-Q Analysis (Version 1.0.6) [Software]. https://shawnbanasick.github.io/ken-q-analysis/ [accessed July 30, 2020].

Eshuis, J., \& Klijn, E. H. (2012). Branding in governance and public management. Routledge. https://doi.org/10.4324/9780203145159

Jeffares, S., \& Skelcher, C. (2011). Democratic subjectivities in network governance: A Q methodology study of English and Dutch public managers. Public Administration 89(4), 1253-73. https://doi.org/10.1111/j.1467-9299.2010.01888.x

Klijn, E. H., \& Stevens, V. (2021). The importance of co-production in branding as governance strategy. In E. Loeffler \& T Bovaird (Eds.), The Palgrave handbook of co-production of public services and outcomes. Palgrave Macmillan. https://doi.org/10.1007/978-3-030-53705-0_8

Lee, B. S. (2017). The fundamentals of Q methodology. Journal of Research Methodology, 2(2), 57-95. https://doi.org/10.21487/jrm.2017.11.2.2.57

McKeown, B., \& Thomas, D. (2013). $Q$ methodology. Sage Publications. https://doi.org/10.4135/9781483384412

Muniz, A. M., \& O’Guinn, T. C. (2001). Brand community. Journal of Consumer Research 27(4), 412-32. https://doi.org/10.1086/319618

Stevens, V., Klijn, E. H., \& Warsen, R. (2020). Branding as a public governance strategy: A Q methodological analysis of how companies react to place branding strategies. Public Administration Review. https://doi.org/10.1111/puar.13263

Stevens, V. (2019). The new method of exponential random graph modelling to analyze interactions in participatory processes of place branding. Marketing Review Journal, 19(2), 1-19. https://doi.org/10.1362/146934719X15633618140747

Stevens, V. (2021). "Replication Data for: How can social branding mitigate racism among fans in sport? A Q-sort analysis on the value of social branding campaigns as vehicles for reducing racism among soccer fans." https://doi.org/10.7910/DVN/RALNJO, Harvard Dataverse, V1.

Watts, S., \& Stenner, P. (2012). Doing Q methodological research: Theory, method, and interpretation. Sage Publications. https://doi.org/10.4135/9781446251911 


\section{Appendix}

Table A1. Factor loadings on all four factors

\begin{tabular}{|c|c|c|c|c|c|}
\hline \multicolumn{6}{|c|}{ Factor matrix ( $\mathbf{X}$ indicates a defining sort) } \\
\hline \multirow[b]{2}{*}{ Q-sort } & \multirow[b]{2}{*}{ Respondent code } & \multicolumn{4}{|c|}{ Factor loadings } \\
\hline & & Factor 1 & Factor 2 & Factor 3 & Factor 4 \\
\hline 1 & 1_Respondent & 0.1026 & 0.3048 & 0.2241 & $0.6545 \mathbf{X}$ \\
\hline 2 & 2_Respondent & $0.6682 X$ & 0.2946 & 0.1367 & 0.4543 \\
\hline 3 & 3_Respondent & 0.0905 & 0.0248 & 0.0433 & $0.5125 \mathbf{X}$ \\
\hline 4 & 4_Respondent & 0.1048 & 0.3845 & 0.0812 & 0.4078 \\
\hline 5 & 5_Respondent & 0.2227 & $0.6352 X$ & -0.1276 & 0.27 \\
\hline 6 & 6_Respondent & 0.5542 & 0.1205 & 0.5354 & 0.4076 \\
\hline 7 & 7_Respondent & 0.3875 & 0.0795 & -0.0168 & 0.2713 \\
\hline 8 & 8_Respondent & $0.5548 \mathrm{X}$ & 0.0795 & 0.2642 & 0.4091 \\
\hline 9 & 9_Respondent & 0.5646 & 0.5319 & 0.0006 & -0.265 \\
\hline 10 & 10_Respondent & 0.1208 & 0.3534 & 0.1128 & 0.1653 \\
\hline 11 & 11_Respondent & 0.332 & 0.271 & 0.2593 & $0.7028 \mathbf{X}$ \\
\hline 12 & 12_Respondent & 0.1569 & $0.9156 \mathbf{X}$ & -0.0815 & 0.0696 \\
\hline 13 & 13_Respondent & -0.0448 & 0.4376 & $0.6263 X$ & -0.0149 \\
\hline 14 & 14_Respondent & 0.0701 & -0.1394 & $0.5489 \mathrm{X}$ & 0.44 \\
\hline 15 & 15_Respondent & $0.5654 X$ & -0.0245 & 0.3699 & 0.1286 \\
\hline 16 & 16_Respondent & 0.4088 & 0.2877 & -0.0752 & 0.4065 \\
\hline 17 & 17_Respondent & $0.4765 \mathbf{X}$ & -0.1158 & 0.0428 & 0.332 \\
\hline 18 & 18_Respondent & 0.4225 & 0.1421 & -0.018 & $0.4679 \mathbf{X}$ \\
\hline 19 & 19_Respondent & $0.8207 \mathbf{X}$ & 0.0916 & 0.0596 & 0.0427 \\
\hline 20 & 20_Respondent & $0.6635 X$ & 0.2101 & 0.366 & 0.0054 \\
\hline 21 & 21_Respondent & 0.1395 & 0.25 & $0.6988 \mathbf{X}$ & 0.2472 \\
\hline 22 & 22_Respondent & $0.4866 \mathrm{X}$ & 0.1135 & 0.2705 & 0.227 \\
\hline 23 & 23_Respondent & -0.0236 & $0.6391 X$ & 0.3913 & 0.1505 \\
\hline 24 & 24_Respondent & 0.238 & 0.142 & $0.5722 X$ & 0.1694 \\
\hline 25 & 25_Respondent & $0.7 \mathbf{X}$ & 0.292 & 0.0955 & -0.0272 \\
\hline 26 & 26_Respondent & $0.5084 \mathrm{X}$ & 0.2201 & 0.1976 & 0.2747 \\
\hline 27 & 27_Respondent & 0.1786 & $0.61 \mathrm{X}$ & 0.2916 & 0.1253 \\
\hline 28 & 28_Respondent & 0.0264 & 0.0732 & 0.2017 & $0.4975 \mathbf{X}$ \\
\hline 29 & 29_Respondent & 0.2833 & -0.1479 & $0.4951 \mathbf{X}$ & 0.001 \\
\hline \multicolumn{2}{|c|}{ Explained variance } & $17 \%$ & $12 \%$ & $10 \%$ & $12 \%$ \\
\hline \multicolumn{2}{|c|}{ Respondents associated with this profile } & 9 & 4 & 5 & 5 \\
\hline
\end{tabular}


Table A2. Factor arrays for our four study factors

\begin{tabular}{|c|c|c|c|c|}
\hline Statement & Factor 1 & Factor 2 & Factor 3 & Factor 4 \\
\hline 1 & -2 & -1 & -2 & -3 \\
\hline 2 & 0 & 0 & 2 & 0 \\
\hline 3 & 2 & 1 & 1 & 0 \\
\hline 4 & 0 & -2 & 0 & -1 \\
\hline 5 & -1 & 1 & -1 & 0 \\
\hline 6 & -2 & -3 & -2 & 0 \\
\hline 7 & 0 & -1 & -1 & -2 \\
\hline 8 & 3 & 2 & 0 & 3 \\
\hline 9 & -1 & -2 & 0 & 1 \\
\hline 10 & -3 & -3 & -3 & -3 \\
\hline 11 & 0 & -2 & 3 & 1 \\
\hline 12 & -3 & 1 & -3 & -2 \\
\hline 13 & 3 & 0 & 1 & -1 \\
\hline 14 & 2 & -1 & -2 & 1 \\
\hline 15 & -2 & 2 & 0 & -2 \\
\hline 16 & 2 & 1 & 2 & 1 \\
\hline 17 & 1 & 0 & -1 & -1 \\
\hline 18 & 1 & 3 & 2 & 2 \\
\hline 19 & 0 & 0 & 1 & 3 \\
\hline 20 & -1 & 0 & 3 & 0 \\
\hline 21 & 0 & 2 & -1 & 2 \\
\hline 22 & 1 & -1 & 0 & 2 \\
\hline 23 & -1 & 0 & 0 & -1 \\
\hline 24 & 1 & 3 & 1 & 0 \\
\hline
\end{tabular}

\section{Copyright Disclaimer}

Copyright for this article is retained by the author(s), with first publication rights granted to the journal.

This is an open-access article distributed under the terms and conditions of the Creative Commons Attribution license (http://creativecommons.org/licenses/by/4.0/). 